\title{
Deciphering the interactions of SARS-CoV-2 proteins with human ion channels using machine learning-based method
}

\section{Nupur S. Munjal}

Institute of Bioinformatics, International Technology Park, Bangalore- 560066, India

\section{Dikscha Sapra}

Institute of Bioinformatics, International Technology Park, Bangalore- 560066, India

\section{Abhishek Goyal}

Institute of Bioinformatics, International Technology Park, Bangalore- 560066, India

\section{K.T. Shreya Parthasarathi}

Institute of Bioinformatics, International Technology Park, Bangalore- 560066, India

\section{Akhilesh Pandey}

Department of Laboratory Medicine and Pathology, Mayo Clinic, Rochester, MN 55905, USA

\section{Manidipa Banerjee}

Kusuma School of Biological Sciences, Indian Institute of Technology Delhi, Hauz Khas, New Delhi, 110016, India

Jyoti Sharma ( $\sim$ jyoti@ibioinformatics.org)

Institute of Bioinformatics, International Technology Park, Bangalore- 560066, India

\section{Research Article}

Keywords: Virus and host, protein interaction networks, cellular pathways, antiviral compounds

Posted Date: August 9th, 2021

DOI: https://doi.org/10.21203/rs.3.rs-622770/v2

License: (1) (1) This work is licensed under a Creative Commons Attribution 4.0 International License. Read Full License

Version of Record: A version of this preprint was published at Pathogens on February 17th, 2022. See the published version at https://doi.org/10.3390/pathogens11020259. 
Deciphering the interactions of SARS-CoV-2 proteins with human ion channels using machine learning-based method

Nupur S. Munjal ${ }^{1}$, Dikscha Sapra ${ }^{1}$, Abhishek Goyal ${ }^{1}$, K.T. Shreya Parthasarathi ${ }^{1}$, Akhilesh Pandey ${ }^{2,3,4}$, Manidipa Banerjee ${ }^{5}$ and Jyoti Sharma ${ }^{1,6^{*}}$

${ }^{1}$ Institute of Bioinformatics, International Technology Park, Bangalore- 560066, India. ${ }^{2}$ Center for Molecular Medicine, National Institute of Mental Health and Neurosciences (NIMHANS), Hosur Road, Bangalore 560 029, India.

${ }^{3}$ Department of Laboratory Medicine and Pathology, Mayo Clinic, Rochester, MN 55905, USA.

${ }^{4}$ Center for Individualized Medicine, Mayo Clinic, Rochester, MN 55905, USA.

${ }^{5}$ Kusuma School of Biological Sciences, Indian Institute of Technology Delhi, Hauz Khas, New Delhi, 110016, India

${ }^{6}$ Manipal Academy of Higher Education (MAHE), Manipal, Karnataka 576104, India.

\section{*Correspondence}

Dr. Jyoti Sharma

Institute of Bioinformatics, International Technology Park, Bangalore- 560066, India; Email:jyoti@ibioinformatics.org 


\section{Abstract}

Severe acute respiratory syndrome coronavirus 2 (SARS-CoV-2) is responsible for the worldwide COVID-19 pandemic which began in 2019. It has a high transmission rate and pathogenicity leading to health emergencies and economic crisis. Recent studies pertaining to the understanding of the molecular pathogenesis of SARS-CoV-2 infection exhibited the indispensable role of ion channels in viral infection inside the host. Moreover, machine learning (ML)-based algorithms are providing higher accuracy for host-SARS-CoV-2 protein-protein interactions (PPIs). In this study, predictions of PPIs of SARS-CoV-2 proteins with human ion channels (HICs) were performed using PPI-MetaGO algorithm. The PPIs were predicted with 82.71\% accuracy, $84.09 \%$ precision, $84.09 \%$ sensitivity, 0.89 AUC-ROC, 65.17\% Matthews correlation coefficient (MCC) score and $84.09 \%$ F1 score. Thereafter, PPI networks of SARSCoV-2 proteins with HICs were generated. Furthermore, biological pathway analysis of HICs interacting with SARS-CoV-2 proteins showed the involvement of six pathways, namely inflammatory mediator regulation of transient receptor potential (TRP) channels, insulin secretion, renin secretion, gap junction, taste transduction and apelin signaling pathway. Our analysis suggests that transient receptor potential cation channel subfamily $M$ member 4 (TRPM4), transient receptor potential cation channel subfamily A member 1 (TRPA1), gap junction protein alpha 1 (GJA1), potassium calcium-activated channel subfamily $\mathrm{N}$ member 4 (KCNN4), acid sensing ion channel subunit 1 (ASIC1) and inositol 1,4,5-trisphosphate receptor type 1 (ITPR1) could serve as an initial set to the experimentalists for further validation. Additionally, various US food and drug administration (FDA) approved drugs interacting with the potential HICs were also identified. The study also reinforces the drug repurposing approach for the development of host directed antiviral drugs.

Key words: Virus and host, protein interaction networks, cellular pathways, antiviral compounds 


\section{Introduction}

SARS-CoV-2 is the reason for the ongoing pandemic which started in 2019. It rapidly spread to more than 175 countries within the first three months (Huang et al. 2020). As of August 2021, more than 200 million confirmed cases have been reported with 4.26 million deaths worldwide (https://coronavirus.jhu.edu/). The dearth of approved treatments specific for SARSCoV-2 infection impeded disease containment measures and control of the spread of infection. Viruses with small-sized genomes in particular, depend on the host genomic machinery for many of their essential functions via interacting with membrane proteins and regulating HICs (Charlton et al. 2020). HICs are transmembrane proteins which allow the passive flow of ions in and out of cells and cellular organelles owing to their electrochemical gradient. Because of the exchange of ions across the membrane that results in electrical currents, ion channels serve a diverse set of roles in generating membrane potential and cellular activities such as, signal transduction, synaptic release of neurotransmitters, hormone release, muscle activity, cell volume regulation motility, and apoptosis (Kim 2014). Dysfunction of HICs leads to a class of diseases called channelopathies (Kim 2014). Numerous viral infections are involved in neuronal pathologies, diarrhoea, cardiomyopathies, bronchitis and pain disorders exploiting a variety of HICs (Charlton et al. 2020).

Ebola and influenza viruses exploit HICs to enter the host by utilizing $\mathrm{Ca}^{2+}$ channels for viral entry (Fujioka et al. 2018; Simmons et al. 2015). Furthermore, activation of host potassium channels during the first six hours of viral infection by Bunyamwera virus were studied (Hover et al. 2017). Likewise, the use of L-type voltage gated $\mathrm{Ca}^{2+}$ channel inhibitor verapamil in the treatment of infection by filoviruses implicated the importance of HICs in viral survival (Hover et al. 2017). Deregulation of potassium channels may result in congenital hyperinsulinism and some rare forms of diabetes (Ashcroft 2005). Most likely, in order to survive and replicate inside a host, viruses must exploit the cellular environment which is highly dependent on the flow of ions into and out of the cell. HICs play a crucial role in viral infection by providing an entry point, supporting viral life cycle and disease progression (Gordon et al. 2020). Moreover, SARS-CoV-2 enters the host by the process of endocytosis and exploits HICs by elevating cytosolic calcium concentration which further aids in viral replication by inhibiting host protein trafficking and maturation of viral proteins (Glebov 2020; Jayaseelan and Paramasivam 2020; Wang et al. 2008).

In view of the host-viral interactions for viral replication there are many host factors that could be potential antiviral targets. Thus, HICs interacting with viral proteins are likely to be more effective antiviral targets. Moreover, the development of HIC-viral interactions provided an 
insight that channelopathies may explain some commonly observed virus induced pathologies (Charlton et al. 2020). Systematic mapping of PPIs of SARS-CoV-2 and human proteins was studied by Gordon et al. for exploring host dependencies of the SARS-CoV-2 virus (Gordon et al. 2020). Furthermore, ML-based algorithms provided the confidence in predicted interactions to improve efficacy of wet lab experiments for drug designing (Sarkar and Saha 2019). PPIs between SARS-CoV-2 proteins and human proteins implementing ML approaches were also reported (Dey et al. 2020; Mei and Zhang 2019; Nourani et al. 2015).

This study focuses on the understanding of the interactome of SARS-CoV-2 proteins with HICs using ML-based algorithms. Protein-protein interaction networks (PPINs) of SARS-CoV-2 proteins with HICs were generated. Moreover, biological pathways analysis of HICs interacting with SARS-CoV-2 proteins was performed. Furthermore, FDA approved drugs interacting with potential HICs were identified. This study could provide an insight towards the better understanding of interaction of SARS-CoV-2 proteins with HICs and also underlines the potential significance of repurposing of drugs.

\section{Prediction of interactions between SARS-CoV-2 proteins and HICs using PPI-MetaGO}

To predict the PPIs between SARS-CoV-2 proteins and HICs a ML-based approach was used. An overview of the methodology followed to study the PPIs between SARS-CoV-2 and HICs is described in Figure 1.

\subsection{Data collection}

One of the most crucial steps while building any model based on a ML algorithm is the extraction and enhancement of a good dataset. Primarily, a list of 28 unique SARS-CoV-2 proteins were downloaded from the RefSeq database and 328 HICs were retrieved using the HGNC database (Bruford et al. 2008). Interactions between HICs and SARS-CoV-2 proteins were parsed using the BioGRID database (release 4.92.192). Dataset included 181 interactions of HICs with SARS-CoV-2 proteins (Supplementary Table 1) and 21 interactions among SARS-CoV-2 proteins (Supplementary Table 2). The positive dataset consists of 202 interactions that were used as input for PPI-MetaGO. PPIs of SARS-CoV-2 proteins with HICs are depicted as a network (Supplementary Figure 1). There are no 'gold standard' negative datasets available. Therefore, for PPIs prediction, protein pairs were chosen randomly from the set of protein pairs that are not known to interact, and treat them as a negative dataset (Ben-Hur and Noble 2006). For the negative set, first the complement graph of the positive interactions was made and random interactions were taken to generate the negative set. Furthermore, the 
protein sequences were parsed using RefSeq database and gene ontology terms for SARS-CoV2 proteins were downloaded from Gene Ontology knowledgebase (Ashburner et al. 2000; Seth Carbon 2021).

\subsection{Feature extraction and stacked generalisation method for prediction}

PPI-MetaGO algorithm (Chen et al. 2019a) was applied for the extraction of features of the protein pairs. It is an ensemble supervised meta learner algorithm for PPI prediction. The feature vectors consisting of physicochemical properties of proteins were extracted using protein sequences. Furthermore, semantic similarities were extracted using the provided GO terms (Chen et al. 2019a).

Dataset was split into a training and testing set of 80:20 ratios. Thereafter, protein sequences and the GO terms were provided as input to the PPI-MetaGO program for the calculation of features and prediction model building. Customized Python scripts were used for the generation of input for PPI-MetaGO. PPI-MetaGO uses a stacked generalisation method that allows combining multiple ML algorithms to maximise accuracy. Usage of a single ML-based method may lead to overfitting or underfitting of data even when the parameters are optimised maximally. Bagging and boosting which allow multiple ML-based algorithms only permit combining algorithms of the same type and focus on reducing the variance from multiple classifiers (Chen et al. 2019a). Stacked generalisation uses a meta-ML model which allows combination of different algorithms and aims to reduce the bias of the base generalisers (Ma et al. 2018). ML-based methods utilized by PPI-MetaGO include random forest, artificial neural network, Naïve Bayes, K-nearest neighbors and support vector machine.

\subsection{Evaluation}

The PPIs were evaluated using the following performance measures:

$$
\begin{aligned}
& \text { Accuracy }=\frac{T P+T N}{T P+T N+F P+F N} \\
& \text { Precision }=\frac{T P}{T P+F P} \\
& \mathrm{~F}-\text { score }=\frac{2 X T P R X \text { Precision }}{T P R+\text { Precision }} \\
& \mathrm{MCC}=\frac{T P X T N-F P X F N}{\sqrt{(T P+F P)(T P+F N)(T N+F P)(T N+F N)}}
\end{aligned}
$$

Sensitivity $=\frac{T P}{T P+F N}$

False Positive Rate $=\frac{F P}{F P+T N}$ 
where TPR, TP, TN, FP, and FN represent true positive rate, true positive, true negative, false positive, and false negative, respectively. In addition, PPI-MetaGO also calculates area under the curve (AUC). AUC is the probability that a random positive sample will have a higher score than a random negative sample. Accuracy of $84.09 \%$ and AUC of 0.89 was obtained for SARSCoV-2 and HIC interactions (Table 1). Confusion matrix obtained for the dataset represents 37 true positives, 7 false positives, 7 false negatives, and 30 true negatives (Table 2).

\section{Protein-protein interactions of SARS-CoV-2 proteins with HICs}

Of the 328 HICs, 40 were found to interact with SARS-CoV-2 proteins. Functions of HICs interacting with SARS-CoV-2 proteins are provided in Supplementary Table 3. ITPR1, inositol 1,4,5-trisphosphate receptor type 2 (ITPR2) and inositol 1,4,5-trisphosphate receptor type 3 (ITPR3) receptors were found to be involved in the release of calcium from the endoplasmic reticulum (ER) (Atakpa et al. 2018; Kuchay et al. 2018; Vervloessem et al. 2015; Wiel et al. 2014). ANO5, ANO6, ANO8, ANO10 belongs to anoctamin family that are calcium dependent channel proteins and may be accountable for the entry of viral proteins into the cells. (Bushell et al. 2019; Ishihara et al. 2016; Jha et al. 2019a; Lin et al. 2019; Lin et al. 2018; Oh and Jung 2016; Veit et al. 2018). Out of 40 HICs, a group of leucine rich volume regulated anion channels were identified. These proteins were involved in various functions such as, B cell development, maintenance of constant cell volume, efflux of amino acids and import of antibiotic blasticidinS into the cells (Chen et al. 2019b; Lee et al. 2014; Lu et al. 2019; Lutter et al. 2017; Schober et al. 2017; Voss et al. 2014). The potassium voltage gated channels are known to act as modulators of potassium flow into the cell and also have a role in reactivation of naïve T-cells (Babenko et al. 1998; Cooper et al. 2017; Delaney et al. 2012; Du et al. 2013; Fu et al. 2017; Maekawa et al. 2014; Mederos et al. 2009; Srivastava et al. 2006; Srivastava et al. 2008; Tammaro and Ashcroft 2007; Yan et al. 2004; Zhang et al. 2016). Proteins belonging to the transient receptor potential cation channel family are known to have a role in signal transduction (Jha et al. 2019b; Xian et al. 2020; Zhao et al. 2020). The TRPM7 is both an ion channel as well as serine/threonine protein kinase (Lee et al. 2020). The proteins belonging to voltage dependent anion channels play a role involving $\mathrm{Ca}^{2+}$ ions during viral entry (Fujioka et al. 2018; Jitobaom et al. 2016; Luzio et al. 2007). Another important voltage gated channel showing interaction with the viral proteins were the chloride voltage gated channels which help in maintaining homeostasis and also contributes to acidification thus maintaining lysosomal $\mathrm{pH}$ (Bourdin et al. 2015; Hansen et al. 2020; Leisle et al. 2011; Muller et al. 2019; Yang et al. 2011). 
Gap junction proteins may be involved in the cell to cell spread of the virus. GJA1 is a component of gap junctions which enables communication between adjacent cells. It was found to interact with M, nsp4, nsp6, ORF7a, ORF7b viral proteins. Viruses destroy cell junctions to invade the host (Dong et al. 2020). Also, another role of gap junctions reported in viral infection, was the amplification of antiviral signaling in neighbouring cells. It was studied that STING dependent recognition was essential for limiting virus replication in influenza virus (Platt et al. 2017). Thus, it could be inferred that gap junctions can act as a port of entry for the virus and may limit the immune reaction against SARS-CoV-2 infection (Ahn and Barber 2019). Also, gap junction proteins play a major role in contraction of the heart (Brink et al. 2020; MartinsMarques et al. 2020; Ye et al. 2017). One of the important HICs found to be interacting was the ASIC1 which is usually involved in learning, pain, sensation, memory and fear (Waldmann et al. 1997). PKD2, TPCN1, HCN2, SCN9A, GRID1, CHRNA5 and MCOLN3 were also identified. These proteins function as calcium permeable cation channel, voltage-gated calcium channels across lysosomal membranes, native pacemaker currents in heart, sodium selective channels allowing $\mathrm{Na}+$ to pass according to electrochemical gradient, channels at synapses and cation channels for inwardly rectifying activity respectively (Ahuja et al. 2015; Brailoiu et al. 2009; Coverstone et al. 2018; Huttlin et al. 2017; Ludwig et al. 1999; Martina et al. 2009; PenaOyarzun et al. 2020). The glycine receptor beta protein is a part of ligand gated chloride channels (Handford et al. 1996). The GABRA5 is a component for heteropentameric receptor for gamma-aminobutyric acid (GABA) and may be involved in GABA-A receptor assembly (Butler et al. 2018).

\subsection{PPIs maps of HICs-SARS-CoV-2 proteins}

Predicted PPIs maps of HICs-SARS-CoV-2 proteins (Figure 2) were visualized using Cytoscape-3.8 (Shannon et al. 2003). E, M, ORF7b, ORF7a and nsp4 (Figure 2 - i, iii, iv, vii and ix) were found to be interacting with ITPR1, ITPR2 and ITPR3. Nsp6 and ORF8 (Figure 2 - viii and $\mathrm{x}$ ) were identified to be interacting with ITPR2 and ITPR3. Also, S and ORF6 (Figure 2 - ii and vi) interacted with ITPR3. Viruses exploiting ITPRs were reported to affect the host by increasing metabolic stress and enterotoxicity (Clark and Eisenstein 2013). Moreover, it was reported that viral infections promote depletion of $\mathrm{ER} \mathrm{Ca}^{2+}$ storage using ITPRs that in turn promote viral replication (Clark and Eisenstein 2013). Interaction of SARS-CoV-2 proteins with ITPRs may promote viral replication inside the host cells.

E, M, ORF7b, ORF3a, ORF7a, nsp6, nsp4 and ORF8 proteins (Figure 2 - i, iii, iv, v, vii, viii, ix and $\mathrm{x}$ ) were found to be interacting with leucine rich repeat containing 8 VRAC subunit A 
(LRRC8A). LRRC8A plays an important role in T-cell/ B-cell development. It also plays a role in development and function of lymphocytes (Platt et al. 2017). Thus, it could be that interaction between LRRC8A and SARS-CoV-2 proteins may play a role in impairment of T-cell development during the course of a disease.

M, ORF3a, nsp6 and nsp4 (Figure 2 - iii, v, viii and ix) were found to be interacting with voltage dependent anion channels VDAC2 and VDAC3 and E, ORF7b, ORF6, ORF7a, nsp14, nsp5 and nsp13 (Figure 2 - i, iv, vi, vii, xii, xiii, xiv) were found to be interacting with VDAC3. Voltage dependent anion channels (VDACs) were found to be involved in transportation of metabolites from mitochondria to ER during viral replication and interacting with structural and non-structural proteins (nsps) of dengue virus (Jitobaom et al. 2016).

It was known that the coronavirus family uses $\mathrm{E}$ protein to induce intracellular membrane remodelling generating new membrane vesicles which serve as a viral replication site. They were responsible for depolarisation of membranes (Arya et al. 2020). Furthermore, E protein helped in budding and release of virus particles (Arya et al. 2020). Likewise, the M protein along with E protein was responsible for the determination of virion assembly (Arya et al. 2020). The nsp3, nsp4 and nsp6 interacting with the HICs were also found to contain a transmembrane domain. These nsps were involved in host membrane remodelling and known to act as membrane anchors for replication and transcription complexes (Angelini et al. 2013; Snijder et al. 2016). This could shed light on the fact that these viral proteins have similar properties and may be involved in host invasion by mimicking the ion channels present in the host. This could as well be attributed to the presence of a signature sequence in the chlorella virus (PBCV-1) Kcv protein that showed architectural similarity with eukaryotic Kir channels (Wang et al. 2010). Hence it is important to understand the function of viroporins in the manipulation of host-specific processes. However, targeting them can be a challenge due to resistance polymorphism exhibited by viruses.

\subsection{The protein-protein interaction networks (PPINs) of HICs-SARS-CoV-2 proteins}

PPINs of HICs interacting with SARS-CoV-2 proteins were generated using STRING database (v11) (Szklarczyk et al. 2019). Furthermore, visualization of PPINs of HICs-SARS-CoV-2 proteins were performed using Cytoscape-3.8 (Shannon et al. 2003). PPINs for the SARS-CoV2 proteins and HICs served in the identification of major HICs that were common interactors of SARS-CoV-2 proteins S, M, E, ORF3a, ORF6, ORF7a, ORF7b, ORF8, nsp4, nsp6 (Figure $3)$. 


\section{Biological interpretation of HICs-SARS-CoV-2 PPINs}

The KEGG PATHWAY analysis of HIC dataset interacting with SARS-CoV-2 proteins was performed using STRING database (v11) and a total forty-one biological pathways were identified. Statistical measures including strength and false discovery rate (FDR) score provided by p-values were considered. And six pathways were further selected for the biological interpretation of PPINs (Table 3).

\subsection{KEGG PATHWAY analysis of HICs interacting with SARS-CoV-2 proteins}

Inflammatory mediator regulations of TRP channels pathway include TRP channels (ITPR1, ITPR2 and ITPR3). TRP channels that respond to temperature are known as thermo-TRPs. Among them TRPA1, TRPM8, TRPV1-4 were found in the nerve endings and play a major role in pain perception. These proteins could be modulated indirectly by inflammatory mediators such as proinflammatory cytokines (Parenti et al. 2016). Activation of TRPV1 increased the release of several pro-inflammatory molecules, including substance $\mathrm{P}(\mathrm{sP})$ and cytokines such as, interleukin-6. Respiratory pathophysiology in SARS-CoV-2 infection may show mechanisms related to TRPV1 receptor sensitization that could result in hyper inflammation of the lungs and associated complication (Groneberg et al. 2004). TRP channels also have role in the transmission of sensory stimuli of taste (Talavera 2015). Furthermore, TRPA1 may increase the sensitivity to evoke pain and several other symptoms associated with SARS-CoV-2 infection (Silvagno et al. 2020). ACE2 and TMPRSS2 expression has been reported in salivary gland cells of the tongue and tonsils. It might allow virus to fuse its membrane with the host cells as compared to other oral tissues (Huang et al. 2021). SARSCoV-2 may cause changes in the production or quality of saliva, contributing to the symptoms of loss of taste in the oral cavity of patients infected with SARS-CoV-2.

Glucose-induced insulin secretion is the main principle of insulin release (Komatsu et al. 2013). Deterioration in glycemic levels including both insulin resistance and impaired insulin secretion were recently reported upon SARS-CoV-2 infection (Gianchandani et al. 2020; Wu et al. 2020). Also, a recent study showed that $A C E 2$ expression increased considerably in human pancreatic beta cells in response to inflammatory cytokines thus rendering the beta cells more susceptible to SARS-CoV-2 infections (Muller et al. 2021). However, roles of HICs including TRPM4, KCNN4, KVNJ11 and ITPR3 need to be explored further.

Gap junctions contain the intercellular channels that allowed a direct communication between the cellular compartments. These channels permitted the direct transfer of ions, amino acids, second messengers and other metabolites between adjacent cells. Change in the intracellular 
$\mathrm{Ca}^{2+}$ levels acted as stimuli to the gap junctions. ITPRs (ITPR1, ITPR2, ITPR3) play a crucial role in maintaining the intracellular $\mathrm{Ca}^{2+}$ as they acted on the ER for the regulation of cytoplasmic calcium concentration (Ivanova et al. 2014).

The renin-angiotensin-aldosterone system (RAAS) is an essential system for electrolyte homeostasis and blood pressure management through the ACE2 axis. Deregulation of RAAS homeostasis resulted in development of distress in lungs, induced apoptosis, vasoconstriction, increased oxidative stress and edema (Gao et al. 2020). ACE2 acted as a port of entry for SARS-CoV-2 (D'Ardes et al. 2020) and its expression decreased as infection progressed. Moreover, reduction in expression level of ACE2 could be correlated to the increase in $\mathrm{Ca}^{2+}$ concentration dependent metalloproteinase domain-containing protein (ADAM10). Furthermore, increase in the $\mathrm{Ca}^{2+}$ concentration could further be attributed to viral proteins interacting with ITPR3 (Scialo et al. 2020). Additionally, decrease in ACE2 level led to accumulation of angiotensin II which further activated angiotensin II type 1 receptor (AT1R) axis thus, worsening the disease outcome. Also, apelin signaling could also be suggested to be involved in disease progression. Apelin peptides are endogenous ligands of G protein coupled receptors APJ. Apelin played a number of roles in the mammalian system by protecting cardiac health and calcium modulation (Wang et al. 2013). Experimental studies exhibited that apelin administration had anti-inflammatory effects (Saeedi Saravi and Beer 2020).

\subsection{Drugs interacting with potential HICs}

HICs interacting with viral proteins could be potential drug targets for drug repurposing. Also, the traditional drug development method is considerably expensive and time consuming. Drug repurposing is an efficacious process by which effective drugs can be identified. The FDA approved drugs interacting with HICs were identified using DGIdb (Freshour et al. 2021; Griffith et al. 2013). Table 4 contains the list of HICs including TRPM4, TRPA1 and ITPR1 interacting with FDA approved drugs. Drugs interacting with HICs were overlaid on HICsSARS-CoV-2 PPINs highlighting potential drug targets (Figure 4). List of drugs interacting with HICs and SARS-CoV-2 protein is listed in Supplementary Table 4. Drugs targeted against HICs can be toxic in some cases (Feng et al. 2004). Furthermore, these drugs can be tested for antiviral activity.

\section{Conclusions}

Several computational approaches including ML-based algorithms were applied to study the interactome of SARS-CoV-2 proteins with HICs. Biological insights of HICs interacting with 
SARS-CoV-2 proteins were gained using pathway analysis. TRPM4 and KCNN4 were found to a play role in insulin secretion. TRPA1 was found as an important molecule in heat, pain, and taste sensitivity inside the host. GJA1 has a crucial role in pathways involving gap junctions and ASIC1 was found to be a part of inflammatory mediator regulation of TRP channels. ITPR1 was found to be involved in four predicted pathways including inflammatory mediator regulation of TRP channels, gap junction, renin secretion and apelin signaling pathways. Moreover, FDA approved drugs interacting with potential HICs were identified. Most likely, our predictions showed promising results that further require experimental validation. HICs could be further explored as a potential class of targets for the better management of infection caused by SARS-CoV-2.

\section{Declarations}

Funding Information: This work was funded by the intramural funds of Institute of Bioinformatics, India and Bio-CARe by Department of Biotechnology (DBT), Government of India, grant number BT/PR19924/BIC/101/568/2016.

Conflict of interest: The authors declare that no competing financial interests exist.

Availability of data and material: Publicly available datasets were analyzed in this study. The data can be accessible using following resources: RefSeq database (https://www.ncbi.nlm.nih.gov/refseq/), BioGRID database (https://thebiogrid.org/) and Gene Ontology knowledgebase (http://geneontology.org/).

Authors' contribution: JS conceptualized and designed the study. NSM, DS, AG, AP, MB and JS analyzed and interpreted the data. NSM, AG, KTSP, AP, MB and JS contributed to the writing of the manuscript and the figures were prepared by KTSP.

Acknowledgements: The authors thank the Department of Biotechnology (DBT), Government of India for research support to the Institute of Bioinformatics (IOB), Bangalore. JS is a recipient of Bio-CARe Women Scientists award by Department of Biotechnology (DBT), Government of India (Grant number-BT/PR19924/BIC/101/568/2016).

\section{References}

Ahn J, Barber GN (2019) STING signaling and host defense against microbial infection Exp Mol Med 51:1-10 doi:10.1038/s12276-019-0333-0

Ahuja $\mathrm{S}$ et al. (2015) Structural basis of Nav1.7 inhibition by an isoform-selective smallmolecule antagonist Science 350:aac5464 doi:350/6267/aac5464

Angelini MM, Akhlaghpour M, Neuman BW, Buchmeier MJ (2013) Severe acute respiratory syndrome coronavirus nonstructural proteins 3, 4, and 6 induce double-membrane vesicles mBio 4 doi:mBio.00524-13 
Arya R et al. (2020) Structural insights into SARS-CoV-2 proteins J Mol Biol 433:166725 doi:S0022-2836(20)30642-2

Ashburner $M$ et al. (2000) Gene ontology: tool for the unification of biology. The Gene Ontology Consortium Nat Genet 25:25-29 doi:10.1038/75556

Ashcroft FM (2005) ATP-sensitive potassium channelopathies: focus on insulin secretion J Clin Invest 115:2047-2058 doi:10.1172/JCI25495

Atakpa P, Thillaiappan NB, Mataragka S, Prole DL, Taylor CW (2018) IP3 Receptors Preferentially Associate with ER-Lysosome Contact Sites and Selectively Deliver $\mathrm{Ca}(2+)$ to Lysosomes Cell Rep 25:3180-3193 e3187 doi:S2211-1247(18)31840-0

Babenko AP, Gonzalez G, Aguilar-Bryan L, Bryan J (1998) Reconstituted human cardiac KATP channels: functional identity with the native channels from the sarcolemma of human ventricular cells Circ Res 83:1132-1143 doi:10.1161/01.res.83.11.1132

Ben-Hur A, Noble WS (2006) Choosing negative examples for the prediction of protein-protein interactions BMC Bioinformatics 7 Suppl 1:S2 doi:1471-2105-7-S1-S2

Bourdin B, Shakeri B, Tetreault MP, Sauve R, Lesage S, Parent L (2015) Functional characterization of CaValpha2delta mutations associated with sudden cardiac death $\mathrm{J}$ Biol Chem 290:2854-2869 doi:S0021-9258(20)49257-9

Brailoiu E et al. (2009) Essential requirement for two-pore channel 1 in NAADP-mediated calcium signaling J Cell Biol 186:201-209 doi:jcb.200904073

Brink PR, Valiunas V, White TW (2020) Lens Connexin Channels Show Differential Permeability to Signaling Molecules Int J Mol Sci 21 doi:ijms21186943

Bruford EA, Lush MJ, Wright MW, Sneddon TP, Povey S, Birney E (2008) The HGNC Database in 2008: a resource for the human genome Nucleic Acids Res 36:D445-448 doi:gkm881

Bushell SR et al. (2019) The structural basis of lipid scrambling and inactivation in the endoplasmic reticulum scramblase TMEM16K Nat Commun 10:3956 doi:10.1038/s41467-019-11753-1

Butler KM, Moody OA, Schuler E, Coryell J, Alexander JJ, Jenkins A, Escayg A (2018) De novo variants in GABRA2 and GABRA5 alter receptor function and contribute to earlyonset epilepsy Brain 141:2392-2405 doi:5046342

Charlton FW, Pearson HM, Hover S, Lippiat JD, Fontana J, Barr JN, Mankouri J (2020) Ion Channels as Therapeutic Targets for Viral Infections: Further Discoveries and Future Perspectives Viruses 12 doi:v12080844

Chen KH, Wang TF, Hu YJ (2019a) Protein-protein interaction prediction using a hybrid feature representation and a stacked generalization scheme BMC Bioinformatics 20:308 doi:10.1186/s12859-019-2907-1

Chen L, Konig B, Liu T, Pervaiz S, Razzaque YS, Stauber T (2019b) More than just a pressure relief valve: physiological roles of volume-regulated LRRC8 anion channels Biol Chem 400:1481-1496 doi:10.1515/hsz-2019-0189

Clark KB, Eisenstein EM (2013) Targeting host store-operated $\mathrm{Ca}(2+)$ release to attenuate viral infections Curr Top Med Chem 13:1916-1932 doi:CTMC-EPUB-54626

Cooper PE, McClenaghan C, Chen X, Stary-Weinzinger A, Nichols CG (2017) Conserved functional consequences of disease-associated mutations in the slide helix of Kir6.1 and Kir6.2 subunits of the ATP-sensitive potassium channel J Biol Chem 292:17387-17398 doi:S0021-9258(20)33896-5

Coverstone ED et al. (2018) A novel genetic marker of decreased inflammation and improved survival after acute myocardial infarction Basic Res Cardiol 113:38 doi:10.1007/s00395-018-0697-7 
D'Ardes D, Boccatonda A, Rossi I, Guagnano MT, Santilli F, Cipollone F, Bucci M (2020) COVID-19 and RAS: Unravelling an Unclear Relationship Int J Mol Sci 21 doi:ijms21083003

Delaney JT, Muhammad R, Blair MA, Kor K, Fish FA, Roden DM, Darbar D (2012) A KCNJ8 mutation associated with early repolarization and atrial fibrillation Europace 14:14281432 doi:eus 150

Dey L, Chakraborty S, Mukhopadhyay A (2020) Machine learning techniques for sequencebased prediction of viral-host interactions between SARS-CoV-2 and human proteins Biomed J 43:438-450 doi:S2319-4170(20)30136-0

Dong D, Xie W, Liu M (2020) Alteration of cell junctions during viral infection Thorac Cancer 11:519-525 doi:10.1111/1759-7714.13344

Du Q et al. (2013) KATP channels are up-regulated with increasing age in human myometrium Mech Ageing Dev 134:98-102 doi:S0047-6374(13)00018-3

Feng JY et al. (2004) Relationship between antiviral activity and host toxicity: comparison of the incorporation efficiencies of 2',3'-dideoxy-5-fluoro-3'-thiacytidine-triphosphate analogs by human immunodeficiency virus type 1 reverse transcriptase and human mitochondrial DNA polymerase Antimicrob Agents Chemother 48:1300-1306 doi:10.1128/AAC.48.4.1300-1306.2004

Freshour SL et al. (2021) Integration of the Drug-Gene Interaction Database (DGIdb 4.0) with open crowdsource efforts Nucleic Acids Res 49:D1144-D1151 doi:6006193

Fu J et al. (2017) Kv2.1 Clustering Contributes to Insulin Exocytosis and Rescues Human betaCell Dysfunction Diabetes 66:1890-1900 doi:db16-1170

Fujioka Y et al. (2018) A Sialylated Voltage-Dependent $\mathrm{Ca}(2+)$ Channel Binds Hemagglutinin and Mediates Influenza A Virus Entry into Mammalian Cells Cell Host Microbe 23:809-818 e805 doi:S1931-3128(18)30216-6

Gao YL et al. (2020) Role of Renin-Angiotensin System in Acute Lung Injury Caused by Viral Infection Infect Drug Resist 13:3715-3725 doi:10.2147/IDR.S265718

Gianchandani R, Esfandiari NH, Ang L, Iyengar J, Knotts S, Choksi P, Pop-Busui R (2020) Managing Hyperglycemia in the COVID-19 Inflammatory Storm Diabetes 69:20482053 doi:dbi20-0022

Glebov OO (2020) Understanding SARS-CoV-2 endocytosis for COVID-19 drug repurposing FEBS J 287:3664-3671 doi:10.1111/febs.15369

Gordon DE et al. (2020) A SARS-CoV-2 protein interaction map reveals targets for drug repurposing Nature 583:459-468 doi:10.1038/s41586-020-2286-9

Griffith M et al. (2013) DGIdb: mining the druggable genome Nat Methods 10:1209-1210 doi:nmeth.2689

Groneberg DA, Niimi A, Dinh QT, Cosio B, Hew M, Fischer A, Chung KF (2004) Increased expression of transient receptor potential vanilloid-1 in airway nerves of chronic cough Am J Respir Crit Care Med 170:1276-1280 doi:10.1164/rccm.200402-174OC

Handford CA, Lynch JW, Baker E, Webb GC, Ford JH, Sutherland GR, Schofield PR (1996) The human glycine receptor beta subunit: primary structure, functional characterisation and chromosomal localisation of the human and murine genes Brain Res Mol Brain Res 35:211-219 doi:0169-328X(95)00218-H

Hansen TH et al. (2020) A Novel Loss-of-Function Variant in the Chloride Ion Channel Gene Clcn2 Associates with Atrial Fibrillation Sci Rep 10:1453 doi:10.1038/s41598-02058475-9

Hover S, Foster B, Barr JN, Mankouri J (2017) Viral dependence on cellular ion channels - an emerging anti-viral target? J Gen Virol 98:345-351 doi:10.1099/jgv.0.000712

https://coronavirus.jhu.edu/. 
Huang C et al. (2020) Clinical features of patients infected with 2019 novel coronavirus in Wuhan, China Lancet 395:497-506 doi:S0140-6736(20)30183-5

Huang $\mathrm{N}$ et al. (2021) SARS-CoV-2 infection of the oral cavity and saliva Nat Med 27:892903 doi:10.1038/s41591-021-01296-8

Huttlin EL et al. (2017) Architecture of the human interactome defines protein communities and disease networks Nature 545:505-509 doi:nature22366

Ishihara K, Suzuki J, Nagata S (2016) Role of $\mathrm{Ca}(2+)$ in the Stability and Function of TMEM16F and 16K Biochemistry 55:3180-3188 doi:10.1021/acs.biochem.6b00176

Ivanova H, Vervliet T, Missiaen L, Parys JB, De Smedt H, Bultynck G (2014) Inositol 1,4,5trisphosphate receptor-isoform diversity in cell death and survival Biochim Biophys Acta 1843:2164-2183 doi:S0167-4889(14)00091-3

Jayaseelan VP, Paramasivam A (2020) Repurposing calcium channel blockers as antiviral drugs J Cell Commun Signal 14:467-468 doi:10.1007/s12079-020-00579-y

Jha A et al. (2019a) Anoctamin 8 tethers endoplasmic reticulum and plasma membrane for assembly of $\mathrm{Ca}(2+)$ signaling complexes at the ER/PM compartment EMBO J 38 doi:embj.2018101452

Jha RM et al. (2019b) Downstream TRPM4 Polymorphisms Are Associated with Intracranial Hypertension and Statistically Interact with ABCC8 Polymorphisms in a Prospective Cohort of Severe Traumatic Brain Injury J Neurotrauma 36:1804-1817 doi:10.1089/neu.2018.6124

Jitobaom K, Tongluan N, Smith DR (2016) Involvement of voltage-dependent anion channel (VDAC) in dengue infection Sci Rep 6:35753 doi:srep35753

Kim JB (2014) Channelopathies Korean J Pediatr 57:1-18 doi:10.3345/kjp.2014.57.1.1

Komatsu M, Takei M, Ishii H, Sato Y (2013) Glucose-stimulated insulin secretion: A newer perspective J Diabetes Investig 4:511-516 doi:10.1111/jdi.12094

Kuchay S et al. (2018) NS5A Promotes Constitutive Degradation of IP3R3 to Counteract Apoptosis Induced by Hepatitis C Virus Cell Rep 25:833-840 e833 doi:S22111247(18)31559-6

Lee CC, Freinkman E, Sabatini DM, Ploegh HL (2014) The protein synthesis inhibitor blasticidin s enters mammalian cells via leucine-rich repeat-containing protein 8D J Biol Chem 289:17124-17131 doi:S0021-9258(20)40682-9

Lee CT, Ng HY, Kuo WH, Tain YL, Leung FF, Lee YT (2020) The role of TRPM7 in vascular calcification: Comparison between phosphate and uremic toxin Life Sci 260:118280 doi:S0024-3205(20)31032-8

Leisle L, Ludwig CF, Wagner FA, Jentsch TJ, Stauber T (2011) ClC-7 is a slowly voltagegated $2 \mathrm{Cl}(-) / 1 \mathrm{H}(+)$-exchanger and requires Ostm1 for transport activity EMBO J 30:2140-2152 doi:emboj2011137

Lin H, Jun I, Woo JH, Lee MG, Kim SJ, Nam JH (2019) Temperature-dependent increase in the calcium sensitivity and acceleration of activation of ANO6 chloride channel variants Sci Rep 9:6706 doi:10.1038/s41598-019-43162-1

Lin H, Roh J, Woo JH, Kim SJ, Nam JH (2018) TMEM16F/ANO6, a Ca(2+)-activated anion channel, is negatively regulated by the actin cytoskeleton and intracellular MgATP Biochem Biophys Res Commun 503:2348-2354 doi:S0006-291X(18)31479-7

$\mathrm{Lu}$ J, Xu F, Zhang J (2019) Inhibition of angiotensin II-induced cerebrovascular smooth muscle cell proliferation by LRRC8A downregulation through suppressing PI3K/AKT activation Hum Cell 32:316-325 doi:10.1007/s13577-019-00260-6

Ludwig A, Zong X, Stieber J, Hullin R, Hofmann F, Biel M (1999) Two pacemaker channels from human heart with profoundly different activation kinetics EMBO J 18:2323-2329 doi:10.1093/emboj/18.9.2323 
Lutter D, Ullrich F, Lueck JC, Kempa S, Jentsch TJ (2017) Selective transport of neurotransmitters and modulators by distinct volume-regulated LRRC8 anion channels J Cell Sci 130:1122-1133 doi:jcs.196253

Luzio JP, Bright NA, Pryor PR (2007) The role of calcium and other ions in sorting and delivery in the late endocytic pathway Biochem Soc Trans 35:1088-1091 doi:BST0351088

Ma Z, Wang P, Gao Z, Wang R, Khalighi K (2018) Ensemble of machine learning algorithms using the stacked generalization approach to estimate the warfarin dose PLoS One 13:e0205872 doi:10.1371/journal.pone.0205872

Maekawa M et al. (2014) Sequential breakdown of 3-phosphorylated phosphoinositides is essential for the completion of macropinocytosis Proc Natl Acad Sci U S A 111:E978987 doi:1311029111

Martina JA, Lelouvier B, Puertollano R (2009) The calcium channel mucolipin-3 is a novel regulator of trafficking along the endosomal pathway Traffic 10:1143-1156 doi:TRA935

Martins-Marques T et al. (2020) EHD1 Modulates Cx43 Gap Junction Remodeling Associated With Cardiac Diseases Circ Res 126:e97-e113 doi:10.1161/CIRCRESAHA.119.316502

Mederos YSM et al. (2009) Mutation of histidine 105 in the T1 domain of the potassium channel Kv2.1 disrupts heteromerization with Kv6.3 and Kv6.4 J Biol Chem 284:46954704 doi:S0021-9258(20)71072-0

Mei S, Zhang K (2019) In silico unravelling pathogen-host signaling cross-talks via pathogen mimicry and human protein-protein interaction networks Comput Struct Biotechnol J 18:100-113 doi:10.1016/j.csbj.2019.12.008

Muller JA et al. (2021) SARS-CoV-2 infects and replicates in cells of the human endocrine and exocrine pancreas Nat Metab 3:149-165 doi:10.1038/s42255-021-00347-1

Muller M et al. (2019) Chikungunya virus requires cellular chloride channels for efficient genome replication PLoS Negl Trop Dis 13:e0007703 doi:10.1371/journal.pntd.0007703

Nourani E, Khunjush F, Durmus S (2015) Computational approaches for prediction of pathogen-host protein-protein interactions Front Microbiol 6:94 doi:10.3389/fmicb.2015.00094

Oh U, Jung J (2016) Cellular functions of TMEM16/anoctamin Pflugers Arch 468:443-453 doi:10.1007/s00424-016-1790-0

Parenti A, De Logu F, Geppetti P, Benemei S (2016) What is the evidence for the role of TRP channels in inflammatory and immune cells? Br J Pharmacol 173:953-969 doi:10.1111/bph.13392

Pena-Oyarzun D, Batista-Gonzalez A, Kretschmar C, Burgos P, Lavandero S, Morselli E, Criollo A (2020) New emerging roles of Polycystin-2 in the regulation of autophagy Int Rev Cell Mol Biol 354:165-186 doi:S1937-6448(20)30011-3

Platt CD et al. (2017) Leucine-rich repeat containing 8A (LRRC8A)-dependent volumeregulated anion channel activity is dispensable for T-cell development and function $\mathrm{J}$ Allergy Clin Immunol 140:1651-1659 e1651 doi:S0091-6749(17)30222-1

Saeedi Saravi SS, Beer JH (2020) Apelin-potential therapy for COVID-19? J Mol Cell Cardiol 145:84-87 doi:S0022-2828(20)30216-9

Sarkar D, Saha S (2019) Machine-learning techniques for the prediction of protein-protein interactions J Biosci 44

Schober AL, Wilson CS, Mongin AA (2017) Molecular composition and heterogeneity of the LRRC8-containing swelling-activated osmolyte channels in primary rat astrocytes $\mathbf{J}$ Physiol 595:6939-6951 doi:10.1113/JP275053 
Scialo F et al. (2020) ACE2: The Major Cell Entry Receptor for SARS-CoV-2 Lung 198:867877 doi:10.1007/s00408-020-00408-4

Seth Carbon ED, et al (2021) The Gene Ontology resource: enriching a GOld mine Nucleic Acids Res 49:D325-D334 doi:6027811

Shannon P et al. (2003) Cytoscape: a software environment for integrated models of biomolecular interaction networks Genome Res 13:2498-2504 doi:10.1101/gr.1239303

Silvagno F, Vernone A, Pescarmona GP (2020) The Role of Glutathione in Protecting against the Severe Inflammatory Response Triggered by COVID-19 Antioxidants (Basel) 9 doi:antiox9070624

Simmons JA, D'Souza RS, Ruas M, Galione A, Casanova JE, White JM (2015) Ebolavirus Glycoprotein Directs Fusion through NPC1+ Endolysosomes J Virol 90:605-610 doi:JVI.01828-15

Snijder EJ, Decroly E, Ziebuhr J (2016) The Nonstructural Proteins Directing Coronavirus RNA Synthesis and Processing Adv Virus Res 96:59-126 doi:S0065-3527(16)30047-1

Srivastava S et al. (2006) Histidine phosphorylation of the potassium channel KCa3.1 by nucleoside diphosphate kinase $\mathrm{B}$ is required for activation of $\mathrm{KCa} 3.1$ and $\mathrm{CD} 4 \mathrm{~T}$ cells Mol Cell 24:665-675 doi:S1097-2765(06)00783-0

Srivastava S, Zhdanova O, Di L, Li Z, Albaqumi M, Wulff H, Skolnik EY (2008) Protein histidine phosphatase 1 negatively regulates $\mathrm{CD} 4 \mathrm{~T}$ cells by inhibiting the $\mathrm{K}+$ channel KCa3.1 Proc Natl Acad Sci U S A 105:14442-14446 doi:0803678105

Szklarczyk D et al. (2019) STRING v11: protein-protein association networks with increased coverage, supporting functional discovery in genome-wide experimental datasets Nucleic Acids Res 47:D607-D613 doi:5198476

Talavera K (2015) TRP Channels as Targets for Modulation of Taste Transduction Springer, Cham:127-140 doi:doi.org/10.1007/978-3-319-18705-1_6

Tammaro P, Ashcroft FM (2007) A mutation in the ATP-binding site of the Kir6.2 subunit of the KATP channel alters coupling with the SUR2A subunit J Physiol 584:743-753 doi:jphysiol.2007.143149

Veit M et al. (2018) Anoctamin-6 regulates ADAM sheddase function Biochim Biophys Acta Mol Cell Res 1865:1598-1610 doi:S0167-4889(18)30287-8

Vervloessem T, Yule DI, Bultynck G, Parys JB (2015) The type 2 inositol 1,4,5-trisphosphate receptor, emerging functions for an intriguing $\mathrm{Ca}(2)(+)$-release channel Biochim Biophys Acta 1853:1992-2005 doi:S0167-4889(14)00434-0

Voss FK et al. (2014) Identification of LRRC8 heteromers as an essential component of the volume-regulated anion channel VRAC Science 344:634-638 doi:science.1252826

Waldmann R, Champigny G, Bassilana F, Heurteaux C, Lazdunski M (1997) A proton-gated cation channel involved in acid-sensing Nature 386:173-177 doi:10.1038/386173a0

Wang C et al. (2013) Apelin protects sarcoplasmic reticulum function and cardiac performance in ischaemia-reperfusion by attenuating oxidation of sarcoplasmic reticulum $\mathrm{Ca} 2+-$ ATPase and ryanodine receptor Cardiovasc Res 100:114-124 doi:cvt160

Wang H, Yang P, Liu K, Guo F, Zhang Y, Zhang G, Jiang C (2008) SARS coronavirus entry into host cells through a novel clathrin- and caveolae-independent endocytic pathway Cell Res 18:290-301 doi:cr200815

Wang K, Xie S, Sun B (2010) Viral proteins function as ion channels Biochim Biophys Acta 1808:510-515 doi:S0005-2736(10)00155-0

Wiel C et al. (2014) Endoplasmic reticulum calcium release through ITPR2 channels leads to mitochondrial calcium accumulation and senescence Nat Commun 5:3792 doi:ncomms4792 
Wu L, Girgis CM, Cheung NW (2020) COVID-19 and diabetes: Insulin requirements parallel illness severity in critically unwell patients Clin Endocrinol (Oxf) 93:390-393 doi:10.1111/cen.14288

Xian W, Wang H, Moretti A, Laugwitz KL, Flockerzi V, Lipp P (2020) Domain zipping and unzipping modulates TRPM4's properties in human cardiac conduction disease FASEB J 34:12114-12126 doi:10.1096/fj.202000097RR

Yan L et al. (2004) Expression of voltage-gated potassium channels in human and rhesus pancreatic islets Diabetes 53:597-607 doi:10.2337/diabetes.53.3.597

Yang L, Katchman A, Morrow JP, Doshi D, Marx SO (2011) Cardiac L-type calcium channel (Cav1.2) associates with gamma subunits FASEB J 25:928-936 doi:fj.10-172353

Ye WG, Yue B, Aoyama H, Kim NK, Cameron JA, Chen H, Bai D (2017) Junctional delay, frequency, and direction-dependent uncoupling of human heterotypic $\mathrm{Cx} 45 / \mathrm{Cx} 43$ gap junction channels J Mol Cell Cardiol 111:17-26 doi:S0022-2828(17)30271-7

Zhang Y et al. (2016) Tannic acid activates the Kv7.4 and Kv7.3/7.5 K(+) channels expressed in HEK293 cells and reduces tension in the rat mesenteric arteries J Pharm Pharmacol 68:494-502 doi:10.1111/jphp.12527

Zhao J, Lin King JV, Paulsen CE, Cheng Y, Julius D (2020) Irritant-evoked activation and calcium modulation of the TRPA1 receptor Nature 585:141-145 doi:10.1038/s41586020-2480-9 
Tables

Table 1: Overall Performance of PPI-MetaGO

\begin{tabular}{|c|c|c|c|c|c|c|}
\hline Accuracy & Precision & F1 Score & AUC-ROC & MCC & Sensitivity & $\begin{array}{c}\text { False Positive } \\
\text { Rate }\end{array}$ \\
\hline 82.71 & 84.09 & 84.09 & 0.89 & 65.17 & 84.09 & 18.91 \\
\hline
\end{tabular}

Table 2: Confusion matrix obtained from PPI-MetaGO

\begin{tabular}{|c|c|c|}
\hline & True Positive & True Negative \\
\hline Predicted Positive & 37 & 7 \\
\hline Predicted Negative & 7 & 30 \\
\hline
\end{tabular}

Table 3: List of KEGG pathways and potential target proteins

\begin{tabular}{|c|c|c|c|}
\hline KEGG Pathway & $\begin{array}{c}\text { Potential Target } \\
\text { Proteins }\end{array}$ & Strength & $\begin{array}{c}\text { False Discovery } \\
\text { Rate }\end{array}$ \\
\hline $\begin{array}{l}\text { Inflammatory mediator } \\
\text { regulation of TRP } \\
\text { channels }\end{array}$ & $\begin{array}{c}\text { ASIC1,TRPA1,ITPR1,ITPR2, } \\
\text { ITPR3 }\end{array}$ & 1.46 & 0.0000328 \\
\hline Taste transduction & GABRA5,ITPR3,SCN9A & 1.29 & 0.0017 \\
\hline Insulin secretion & $\begin{array}{c}\text { TRPM4,KCNN4,KCNJ11, } \\
\text { ITPR3 }\end{array}$ & 1.4 & 0.00022 \\
\hline Gap junction & GJA1,ITPR1,ITPR3,ITPR2 & 1.39 & 0.00022 \\
\hline Renin secretion & ITPR1,ITPR3,ITPR2 & 1.4 & 0.0012 \\
\hline $\begin{array}{l}\text { Apelin signaling } \\
\text { pathway }\end{array}$ & ITPR1,ITPR3,ITPR2 & 1.08 & 0.004 \\
\hline
\end{tabular}


Table 4: List of drugs associated with potential target proteins and processes involved

\begin{tabular}{|c|c|c|c|}
\hline & Drug Name & Target Protein & $\begin{array}{l}\text { Biological } \\
\text { Processes }\end{array}$ \\
\hline 1 & $\begin{array}{c}\text { Adenosine Diphosphate, Clotrimazole, } \\
\text { Adenosine, Spermine, Adenosine } \\
\text { Triphosphate, Glyburide }\end{array}$ & TRPM4 & Insulin secretion \\
\hline 2 & $\begin{array}{c}\text { Thymol, Benzoquinone, Chloropicrin, } \\
\text { Allicin, Morphanthridine, Polygodial, } \\
\text { Methylglyoxal, Isovelleral, Acrolein, } \\
\text { Nicotine, Menthol, Acetaldehyde, Salirasib, } \\
\text { Auranofin, Apomorphine, Cannabidivarin, } \\
\text { Tetrahydrocannabivarin, Levomenthol, } \\
\text { Butamben, Camphor, Cannabidiol, } \\
\text { Nabiximols, Phenethylisothiocyanate, Benzyl } \\
\text { isothiocyanate, Isopropyl isothiocyanate, } \\
\text { Voacangine, Erucin, Allyl isothiocyanate, 4- } \\
\text { Hydroxynon-2-enal }\end{array}$ & TRPA1 & $\begin{array}{c}\text { Inflammatory } \\
\text { mediator } \\
\text { regulation of TRP } \\
\text { channels }\end{array}$ \\
\hline 3 & $\begin{array}{l}\text { Carbenoxolone, Octanol, Carvedilol, } \\
\text { Epigalocatechin Gallate, Bleomycin, } \\
\text { Propylthiouracil, Labetalol, Atenolol }\end{array}$ & GJA1 & Gap junction \\
\hline 4 & $\begin{array}{l}\text { Chlorzoxazone, Senicapoc, Clotrimazole, } \\
\text { Nitredipine, Riluzole, Quinine, Halothane }\end{array}$ & KCNN4 & Insulin secretion \\
\hline 5 & $\begin{array}{c}\text { Diminazene, Amiloride, Ibuprofen, } \\
\text { Nafamostat, Benzamil }\end{array}$ & ASIC1 & $\begin{array}{c}\text { Inflammatory } \\
\text { mediator } \\
\text { regulation of TRP } \\
\text { channels }\end{array}$ \\
\hline 6 & $\begin{array}{c}\text { Caffeine, Adenosine Triphosphate, } \\
\text { Nitroprusside, Glycerin, }\end{array}$ & ITPR1 & $\begin{array}{c}\text { Renin secretion, } \\
\text { Apelin signaling } \\
\text { pathway }\end{array}$ \\
\hline
\end{tabular}




\section{Figure Legends}

Fig. 1 A schematic overview of several analyses carried out to study the interactome of SARSCoV-2 proteins with human ion channels

Fig. 2 A depiction of protein-protein interactions of SARS-CoV-2 proteins (i) E (ii) S (iii) M (iv) ORF7b (v) ORF3a (vi) ORF6 (vii) ORF7a (viii) nsp6 (ix) nsp4 (x) ORF8 (xi) nsp3 (xii) nsp14 (xiii) nsp5 (xiv) nsp13 and (xv) nsp16 with human ion channels (HICs). Yellow colour diamond shaped node represents SARS-CoV-2 proteins and HICs are represented as blue colour diamond

Fig. 3 A schematic representation of protein-protein interaction networks of human-SARSCoV-2 proteins: proteins-proteins interactions of human ion channels (HICs) were generated using STRING database (purple colour nodes). Furthermore, HICs interaction networks were overlaid with SARS-CoV-2 proteins (i) M, (ii) E, (iii) ORF7a (iv) S, (v) ORF6, (vi) ORF3a, (vii) ORF8, (viii) ORF7b, (ix) nsp6 and (x) nsp4. Yellow colour node represents SARS-CoV2 proteins and human ion channels are represented in purple colour node

Fig. 4 Representation of human ion channels-drug target network: Significant interactions between SARS-CoV-2 proteins (i) M, (ii) E, (iii) ORF7a, (iv) nsp6, (v) S, (vi) ORF8, (vii) ORF7b and (viii) nsp4 (yellow colour nodes), potential human ion channels (HICs) (blue colour nodes), and FDA approved drugs (black) as identified by DGIdb. HICs-drug interactions were overlaid on protein-protein interaction networks and potential drug-target interactions are presented in the network 


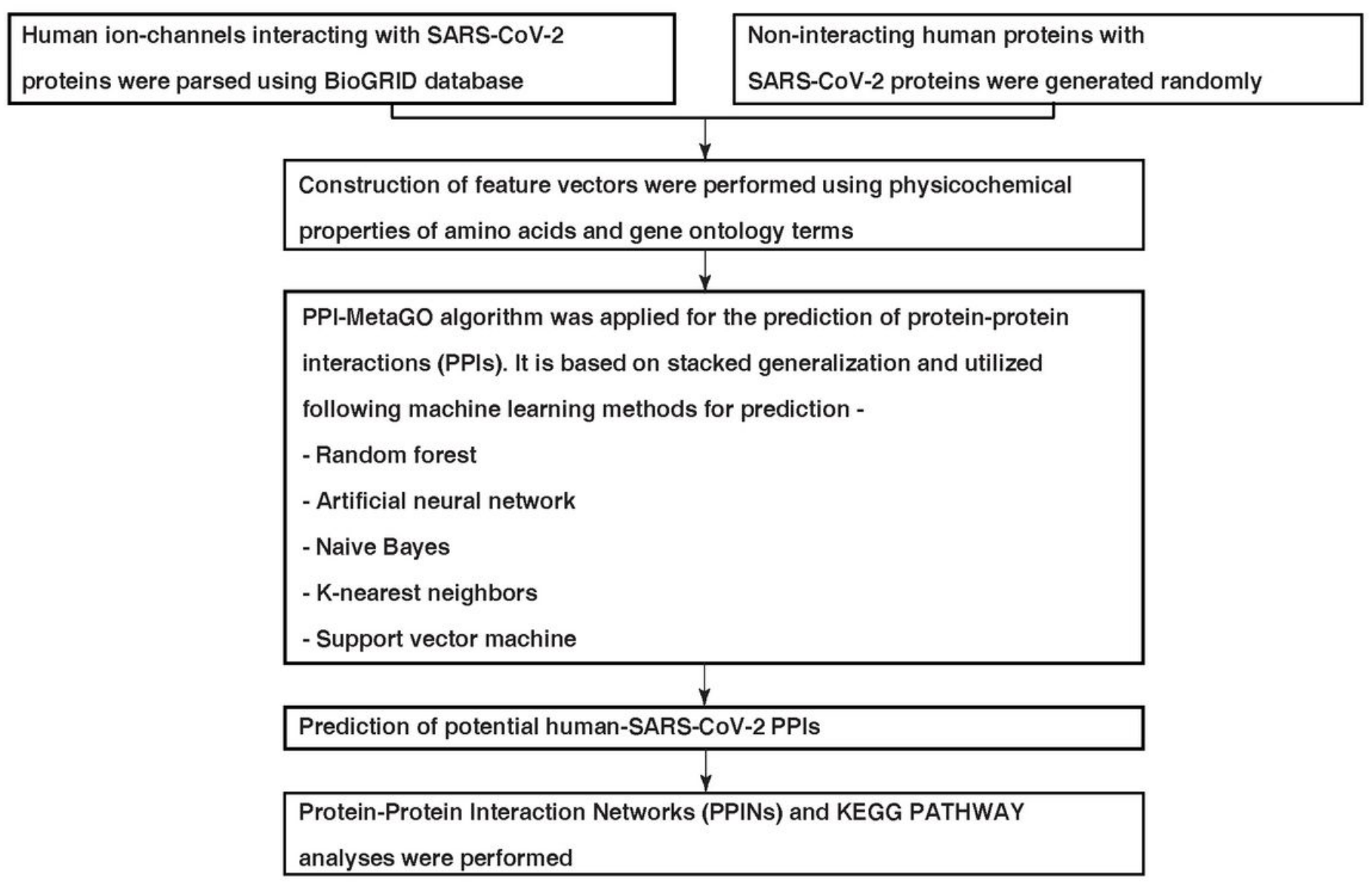

\section{Figure 1}

A schematic overview of several analyses carried out to study the interactome of SARSCoV-2 proteins with human ion channels 

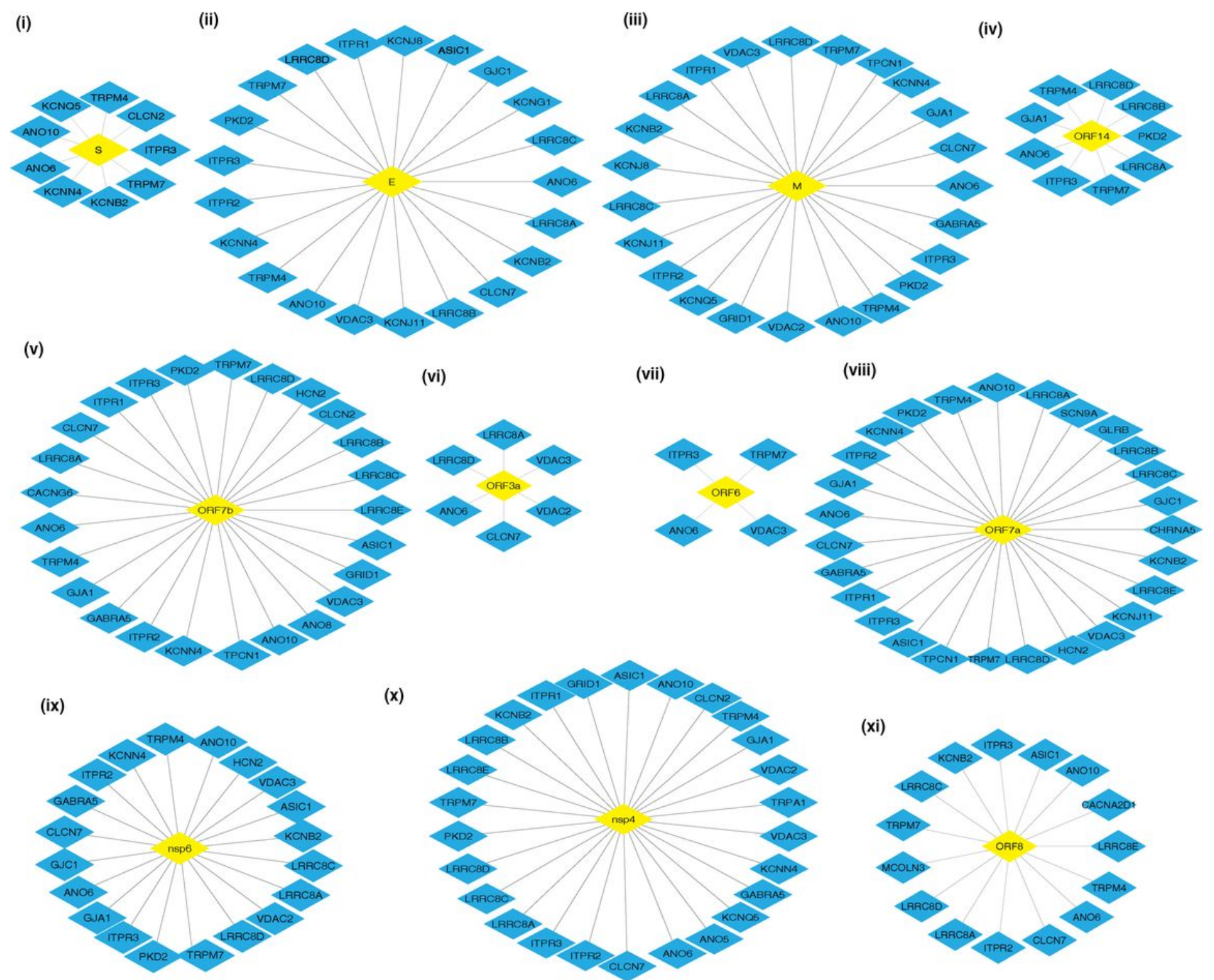

$(\mathrm{x})$

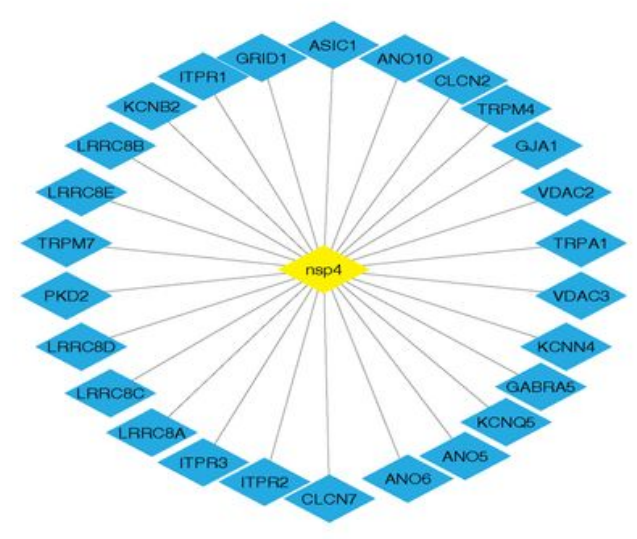

(xii)

(xiii)

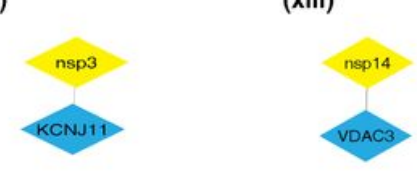

(xiv)

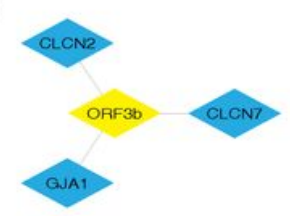

(xv)

(xvi)

(xi)

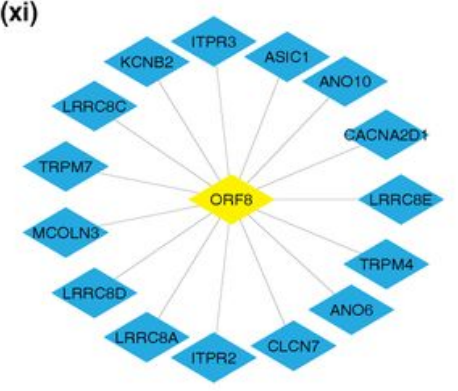

(xvii)
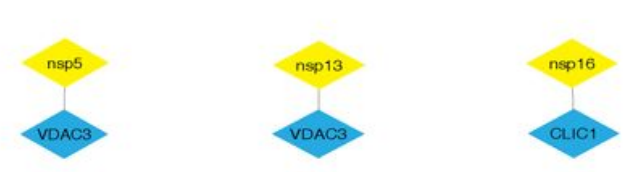

\section{Figure 2}

A depiction of protein-protein interactions of SARS-CoV-2 proteins (i) E (ii) S (iii) M (iv) ORF7b (v) ORF3a (vi) ORF6 (vii) ORF7a (viii) nsp6 (ix) nsp4 (x) ORF8 (xi) nsp3 (xii) nsp14 (xiii) nsp5 (xiv) nsp13 and (xv) nsp16 with human ion channels (HICs). Yellow colour diamond shaped node represents SARS-CoV-2 proteins and HICs are represented as blue colour diamond 

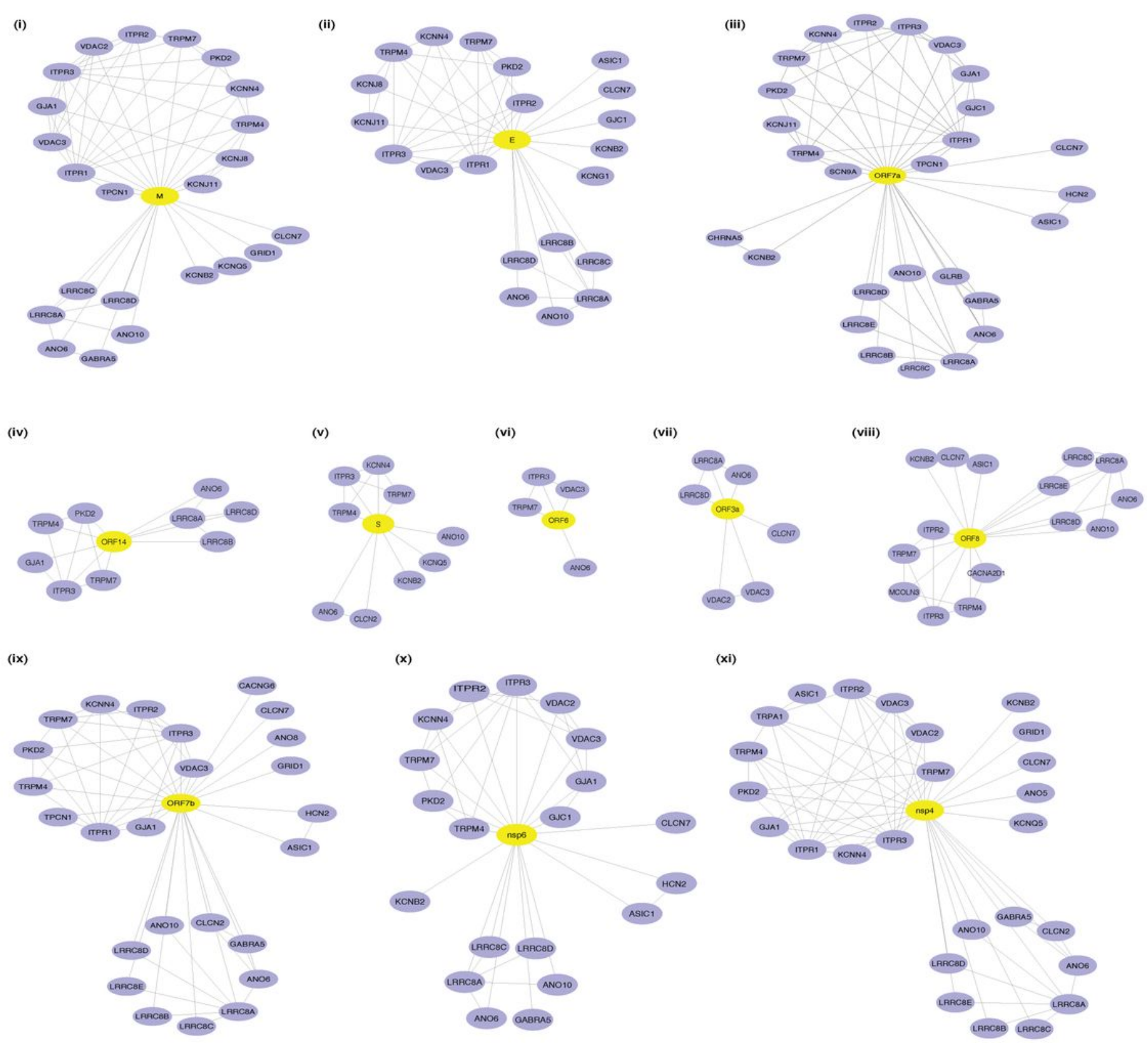

\section{Figure 3}

A schematic representation of protein-protein interaction networks of human-SARSCoV-2 proteins: proteins-proteins interactions of human ion channels (HICs) were generated using STRING database (purple colour nodes). Furthermore, HICs interaction networks were overlaid with SARS-CoV-2 proteins (i) M, (ii) E, (iii) ORF7a (iv) S, (v) ORF6, (vi) ORF3a, (vii) ORF8, (viii) ORF7b, (ix) nsp6 and (x) nsp4. Yellow colour node represents SARS-CoV2 proteins and human ion channels are represented in purple colour node 

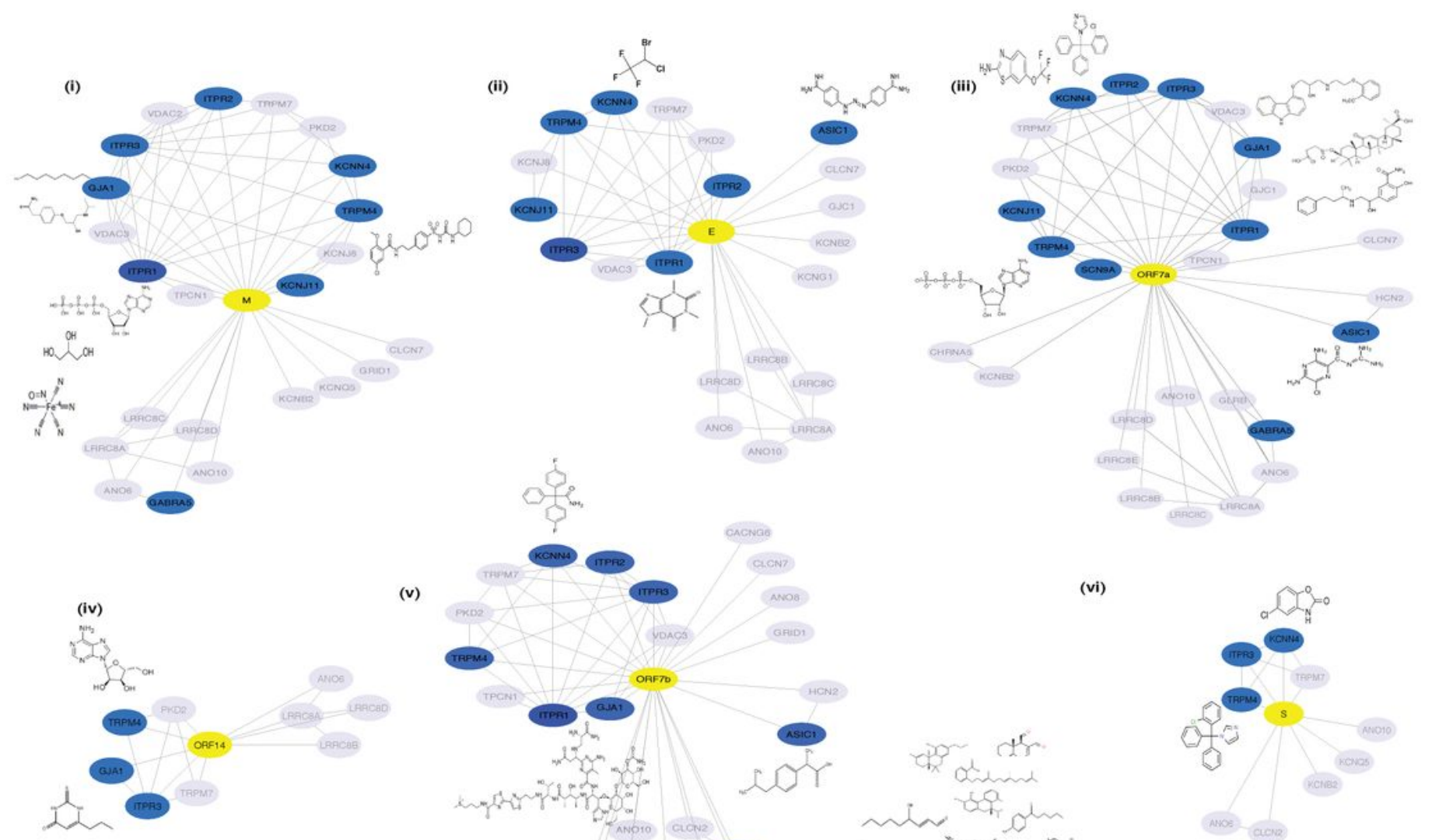

(v)

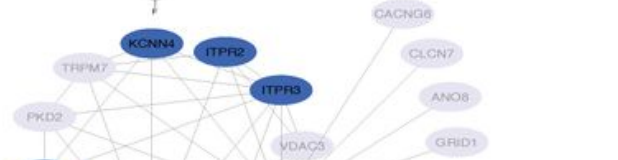

(vi)
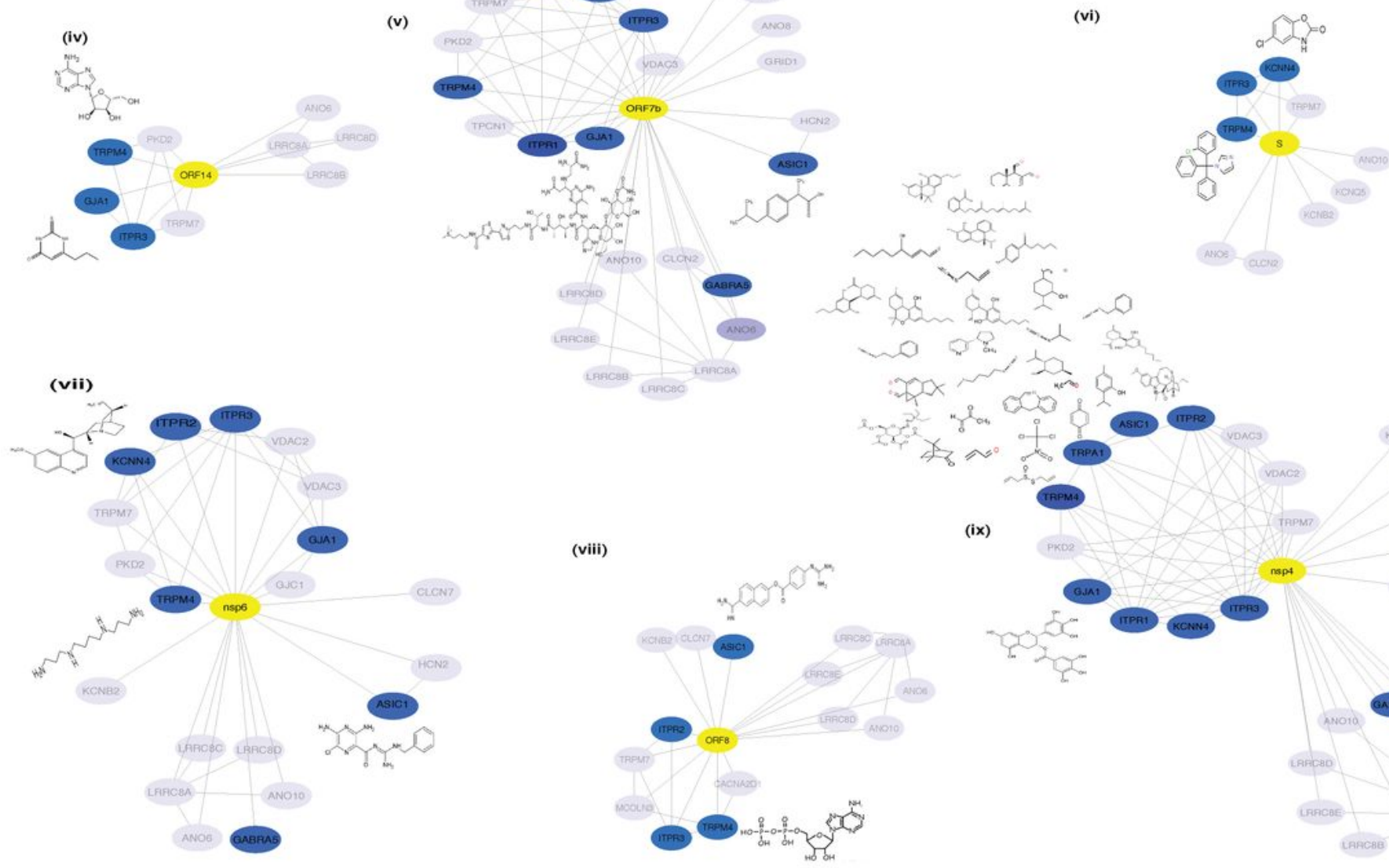

(ix)

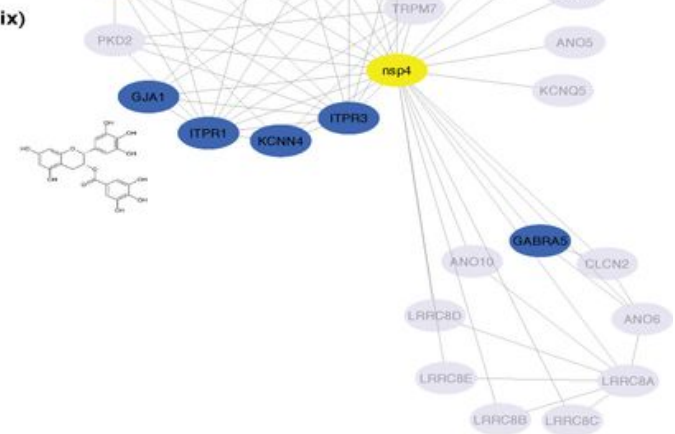

\section{Figure 4}

Representation of human ion channels-drug target network: Significant interactions between SARS-CoV-2 proteins (i) M, (ii) E, (iii) ORF7a, (iv) nsp6, (v) S, (vi) ORF8, (vii) ORF7b and (viii) nsp4 (yellow colour nodes), potential human ion channels (HICs) (blue colour nodes), and FDA approved drugs (black) as identified by DGIdb. HICs-drug interactions were overlaid on protein-protein interaction networks and potential drug-target interactions are presented in the network 


\section{Supplementary Files}

This is a list of supplementary files associated with this preprint. Click to download.

- Supplementaryinformation.pdf 